\title{
The synthesis of alkyl aryl nitriles from $N$-(1-arylalkylidene)- cyanomethylamines. Part 2. Mechanism
}

\author{
Alvise Perosa, Maurizio Selva * and Pietro Tundo
}

Dipartimento di Scienze Ambientali, Università Ca' Foscari, Dorsoduro 2137-30123, Venezia,

Italy.E-mail: selva@unive.it; Fax: +39-041-234 8620; Tel: +39-041-2348687

Received (in Cambridge, UK) 13th July 2001, Accepted 1st March 2002
First published as an Advance Article on the web 2nd April 2002

The mechanism of the rearrangement of $N$-(1-arylalkylidene)cyanomethylamines $\operatorname{ArC}\left(=\mathrm{NCH}_{2} \mathrm{CN}\right) \mathrm{R} 1$ to the corresponding nitriles $\mathrm{ArCH}(\mathrm{CN}) \mathrm{R} 2$ (in DMF, at $150^{\circ} \mathrm{C}$, with $\mathrm{K}_{2} \mathrm{CO}_{3}$ ) is described. Reaction $\mathbf{1} \longrightarrow \mathbf{2}$ was investigated for different types of imine $\mathbf{1}$, and it was found that with a leaving group other than $\mathrm{CN}^{-}$the reaction does not proceed to yield the nitrile, whereas imines such as $\mathrm{PhC}\left(=\mathrm{NCH}_{2} \mathrm{CN}\right) \mathrm{H}$, prepared starting from aldehydes rather than ketones, yield the expected phenylacetonitrile even at temperatures as low as $120^{\circ} \mathrm{C}$. Evidence for the mechanism comes from a study of the reactivity of the postulated intermediates: 2-cyano-3-phenylaziridine 4c, and 2,2-diphenyl$2 \mathrm{H}$-azirine $\mathbf{5 b}$. The route involving aziridine $\mathbf{4 c}$ is ruled out, since this compound does not react at all under the investigated conditions. The $2 \mathrm{H}$-azirine $\mathbf{5 b}$ instead, yields the corresponding diphenylacetonitrile in DMF with $\mathrm{K}_{2} \mathrm{CO}_{3}$, at $150^{\circ} \mathrm{C}$. The transformation seems to involve an initial deprotonation, followed by an intramolecular ring closure- $\mathrm{CN}$ elimination step, which yields the $2 H$-azirine. The azirine then isomerizes to the nitrile. Additional evidence for the intermediacy of the $2 \mathrm{H}$-azirine, based on ${ }^{1} \mathrm{H}$ NMR monitoring of the reaction $\mathbf{1} \longrightarrow \mathbf{2}$, is described. Finally, the results of a simple isotope exchange experiment provide a rationale for the previously observed scrambling of labels, and further confirm the proposed mechanism.

\section{Introduction}

We have recently reported a new reaction of $N$-(1-arylalkylidene)cyanomethylamines $\mathrm{ArC}\left(=\mathrm{NCH}_{2} \mathrm{CN}\right) \mathrm{R} \mathrm{1:}{ }^{1}$ when $\mathbf{1}$ is heated in DMF in the presence of potassium carbonate, it undergoes a clean rearrangement to alkyl aryl nitriles $[\mathrm{ArCH}-$ $(\mathrm{CN}) \mathrm{R}, 2]$ (Scheme 1). The reaction proceeds only at relatively

$$
\begin{aligned}
& \overbrace{\mathrm{R}}^{\mathrm{N}} \widehat{\mathrm{CN}}_{\mathrm{K}} \mathrm{KO}_{3} \frac{\mathrm{DMF}}{150^{\circ} \mathrm{C}}{ }_{\mathrm{Ar}} \overbrace{\mathrm{R}}^{\mathrm{CN}}+\mathrm{KCN}+\mathrm{KHCO}_{3} \\
& 1 \\
& 2 \\
& \text { E.g. 1a, 2a: } \mathrm{Ar}=\mathrm{Ph}, \mathrm{R}=\mathrm{CH}_{3} ; \mathbf{1 b}, \mathbf{2 b}: \mathrm{Ar}=\mathrm{R}=\mathrm{Ph}
\end{aligned}
$$

Scheme 1 Rearrangement of $N$-(1-arylalkylidene)cyanomethylamines to alkyl aryl nitriles.

high temperatures $\left(T \geq 150{ }^{\circ} \mathrm{C}\right)$, through the formal loss of $\mathrm{HCN}$, and both alkyl aryl-, substituted alkyl aryl-, and diarylimines 1 can be used as reagents. ${ }^{2}$

In a previous paper on the mechanism of the $\mathbf{1} \longrightarrow \mathbf{2}$ rearrangement, some unequivocal mechanistic evidence was collected through the investigation of the reaction kinetics and through the study of the reactivity of $\mathrm{N}$-alkylformimidoyl cyanides $[\mathrm{ArCH}(\mathrm{N}=\mathrm{CHCN}) \mathrm{R}],{ }^{3}$ and of labeled imines [ArC$\left(=\mathrm{NCH}_{2}{ }^{13} \mathrm{CN}\right) \mathrm{R}\left({ }^{*} 1\right)$ and $\left.\operatorname{ArC}\left(={ }^{14} \mathrm{NCH}_{2} \mathrm{CN}\right) \mathrm{R}\left(1^{*}\right)\right] .{ }^{4}$ In particular, it was concluded that:

(1) the first, and rate-determining step of the mechanism was deprotonation at the methylene of imines $\mathbf{1}$ to yield $\mathbf{1}^{-}$. This was derived from the Hammett free-energy relationship obtained from the reactions of different $p$-substituted $N$-(1-arylethylidene)cyanomethylamines $1\left(\mathrm{Ar}=p-\mathrm{BrC}_{6} \mathrm{H}_{4^{-}}, p-\mathrm{ClC}_{6} \mathrm{H}_{4^{-}}\right.$, $p-\mathrm{CH}_{3} \mathrm{C}_{6} \mathrm{H}_{4^{-}}$and $p-\mathrm{CH}_{3} \mathrm{OC}_{6} \mathrm{H}_{4^{-}} ; \mathrm{R}=\mathrm{CH}_{3}$ ). The reaction was first order and fitted the Hammett equation $\left(\log k / k_{\mathrm{o}}=\sigma \rho\right)$, giving a $\rho$ value of 1.86 , consistent with the fact that an electron withdrawing group (EWG) on the aryl ring stabilizes the developing negative charge in $\mathbf{1}^{-}$. This observation rules out any mechanisms initiated by an $\mathrm{S}_{\mathrm{N}} 1^{\prime}$ or $\mathrm{S}_{\mathrm{N}} 2^{\prime}$ isomerization, such as the one depicted in Scheme 2.

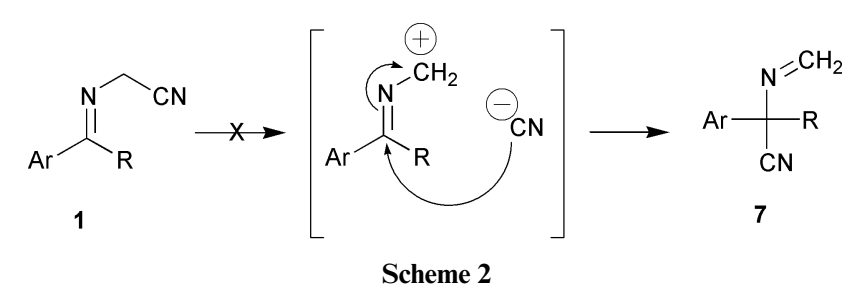

In compound 7, the aryl ring is not conjugated to the reactive site, a fact not compatible with the large positive $\rho$ value obtained by the Hammett treatment. In addition, when imine 1 (with $\mathrm{R}=\mathrm{Ar}=\mathrm{Ph}$ ) was deprotonated with $n$-BuLi in THF at $-90{ }^{\circ} \mathrm{C}$, and then heated at the reflux temperature of THF $\left(67^{\circ} \mathrm{C}\right)$, no reaction was observed. However, when THF was replaced with DMF, and the solution refluxed at $150{ }^{\circ} \mathrm{C}$, the usual clean rearrangement to nitrile $\mathrm{Ph}_{2} \mathrm{CH}(\mathrm{CN}) 2$ was observed.

(2) The cyano group of $\mathrm{ArC}\left(=\mathrm{NCH}_{2} \mathrm{CN}\right) \mathrm{R}$ acted as the leaving group. In fact cyanide was titrated at the end of the reaction, and when it was replaced with other substituents (e.g. phenyl), reaction $\mathbf{1} \longrightarrow \mathbf{2}$ did not take place.

(3) The process was mainly intramolecular and the cyano functionality of nitriles $\mathbf{2}$ derived primarily from the methyleneimino $\left(=\mathrm{NCH}_{2}-\right)$ fragment of $\mathbf{1}$. This was inferred by running a series of reactions using isotopically labeled $\mathrm{PhC}\left(=\mathrm{NCH}_{2}\right.$ $\left.{ }^{13} \mathrm{CN}\right) \mathrm{CH}_{3}$, and $\mathrm{PhC}\left(={ }^{15} \mathrm{NCH}_{2} \mathrm{CN}\right) \mathrm{CH}_{3}$, under the conditions of Scheme 1. The isotope distribution in the two products $\left[\mathrm{PhCH}\left(\mathrm{CH}_{3}\right)^{13} \mathrm{CN}\right]$ and $\left[\mathrm{PhCH}\left(\mathrm{CH}_{3}\right) \mathrm{C}^{15} \mathrm{~N}\right]$ showed enrichments of 32 and $57 \%$, respectively.

Accordingly, two possible reaction pathways were proposed (Scheme 3). They involved the common initial formation of an aziridine ring system, either followed by expulsion of $\mathrm{CN}^{-}$to give a $2 \mathrm{H}$-azirine, and isomerization to the nitrile (path a); or by loss of cyanide through a symmetrical intermediate, and rearrangement to the nitrile (path b). ${ }^{4}$ Although path a appeared more elegant and would somewhat account for the predominant source of $\mathrm{CN}^{-}$, the experimental evidence was not conclusive in its favor. In the present work the proposed 


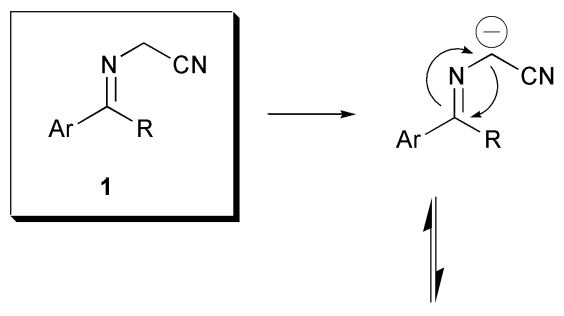

path "b"

$+\mathrm{H}^{+}$
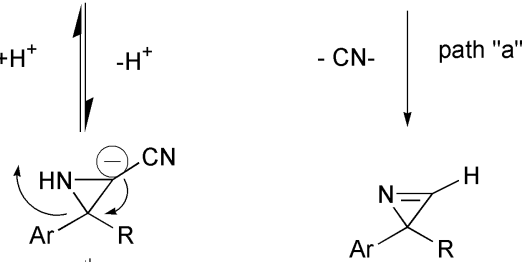

4<smiles>C1=CCCC1</smiles><smiles>[R]/C([Te])=C(/N)C#N</smiles>
$-\mathrm{H}+$

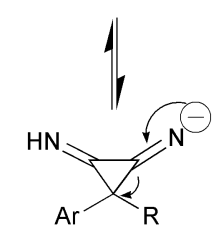

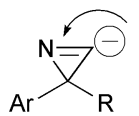

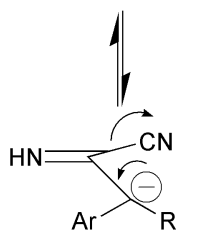<smiles>C1CCCCC1</smiles><smiles>[R]C([Te])=C=NC</smiles>

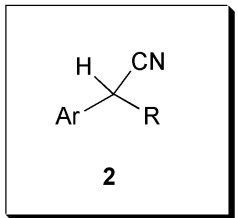

Scheme 3 Two possible pathways for the $\mathbf{1} \longrightarrow \mathbf{2}$ rearrangement.

intermediacy of an azirine in the mechanism of the reaction $\mathbf{1} \longrightarrow \mathbf{2}$, was tested and the results are reported. The behavior of representative examples of the proposed intermediates, synthesized independently by other routes, is described. The outcome of the reaction on substrates with different leaving groups (other than cyano), as well as extension of the process to aldehyde derivatives $\left[\mathrm{PhC}\left(=\mathrm{NCH}_{2} \mathrm{CN}\right) \mathrm{H}\right]$ will be discussed. Finally, a new experiment is described to explain the observed isotope scrambling.

\section{Results and discussion}

Before exploring the reactivity of aziridines and azirines - the proposed intermediates - attention was focused on determining how general the examined reaction could be. Thus, functionalized imines of general formula $\mathrm{PhC}\left(=\mathrm{NCH}_{2} \mathrm{X}\right) \mathrm{R}$ were considered. To understand whether nitriles would still be observable as products and consequently, whether azirines were possible intermediates for such compounds, different $\mathrm{X}$ groups, as well as an aldehyde derivative, $\mathrm{PhC}\left(=\mathrm{NCH}_{2} \mathrm{CN}\right) \mathrm{H}$, were investigated.

\section{Alternative $\mathbf{X}$ groups}

In view of the proposed mechanism, whereby the $\mathrm{CN}$ moiety of the reagent $\mathrm{ArC}\left(=\mathrm{NCH}_{2} \mathrm{CN}\right) \mathrm{R} \mathbf{1}$ is expelled during the reaction, other groups able to stabilize the negative charge on the methylene were considered in place of $\mathrm{CN}$. Compounds $\mathrm{PhC}\left(=\mathrm{NCH}_{2} \mathrm{X}\right) \mathrm{Me}\left(\mathrm{X}=\mathrm{CO}_{2} \mathrm{Me},{ }^{1} \mathbf{3} \mathbf{a} ; \mathrm{CF}_{3}, \mathbf{3 b}\right)$ were prepared by condensation of acetophenone with hydrochloride salts of glycine methyl ester and of 2,2,2-trifluoroethylamine, $\dagger$ respectively. The synthesis of the mesyl $(\mathrm{X}=\mathrm{Ms})$, tosyl $(\mathrm{X}=\mathrm{Ts})$, and oxazole derivatives was attempted, with no success as of yet.

Imines 3a,b were made to react under the conditions of Scheme 1, and would have been expected to yield the corresponding nitrile $\mathrm{PhCH}(\mathrm{CN}) \mathrm{CH}_{3}$ 2a. Compound 3a proved to be completely unreactive: it was recovered unchanged without any other reaction having taken place: a result likely due to the poor leaving group ability of the $-\mathrm{COOCH}_{3}$ group. ${ }^{5} \mathrm{Compound}$ $\mathbf{3 b}$, possessing an electron withdrawing $\mathrm{CF}_{3}$ group able to promote deprotonation and perhaps to act as a leaving group, ${ }^{6}$ did not yield the expected nitrile 2a either; however, it did undergo base-promoted HF elimination to the corresponding conjugated product [eqn. (1)].

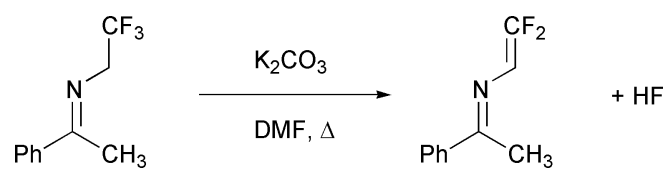

Under the same reaction conditions, a similar product was observed for $\mathrm{PhCH}(\mathrm{Me}) \mathrm{N}=\mathrm{CHCCl}_{3}$ (3f). $\S$ In this case, compound $3 f$ underwent a 1,4-elimination of $\mathrm{HCl}$ to yield $\mathrm{PhC}$ $\left(=\mathrm{NCH}=\mathrm{CCl}_{2}\right) \mathrm{Me}(\mathbf{3 g})$ as the product; behavior analogous to that of base-promoted reactions of $7 \alpha$-amino-1-oxacephems. ${ }^{7}$

On the whole, since no other groups but cyano were suitable for this reaction, it appeared that the presence of electron withdrawing groups capable of negative charge stabilization was not enough to promote the examined reaction: the $\mathrm{X}$ group must also have leaving group ability. This dual behavior of $\mathrm{CN}$ as (a) negative charge stabilizer and (b) leaving group, has an analogy in the benzoin condensation, where cyanide first promotes $\alpha$-deprotonation, and then acts as a leaving group. ${ }^{8}$

\section{Imines derived from aldehydes}

In order to investigate the possible effect of the alkyl group (R) on the iminic carbon, analogs of imines 1 were considered. Specifically, $\mathrm{PhC}\left(=\mathrm{NCH}_{2} \mathrm{CN}\right) \mathrm{H}$ 1c $(\mathrm{R}=\mathrm{H})$ was prepared starting from benzaldehyde following the usual procedure. ${ }^{1}$ When reacted under the conditions of Scheme 1, compound 1c proved much more reactive than methyl aryl imines $\mathbf{1}$, and it was converted very quickly (10 min) into phenylacetonitrile $2 \mathbf{c}(66 \%)$. The double bond isomer of the reagent $\mathrm{PhCH}_{2} \mathrm{~N}=\mathrm{CHCN} \mathbf{1} \mathbf{c}_{\mathbf{i}}$ (24\%) appeared as a by-product, implying that the isomerization $\mathbf{1 c} \rightarrow \mathbf{1} \mathbf{c}_{\mathrm{i}}$ - forbidden for ketone derivatives - took place in this case. However, the rearrangement of $1 \mathbf{c}$ to $2 \mathbf{c}$ proved feasible at a lower temperature $\left(80{ }^{\circ} \mathrm{C}\right.$ instead of $150{ }^{\circ} \mathrm{C}$; conversion: $84 \%$; 2 c: $78 \%$, after $180 \mathrm{~min})$, thereby drastically decreasing $\mathbf{1} \mathbf{c}_{\mathbf{i}}$ formation $(6 \%)$.

$\dagger$ Compounds $\mathbf{3 a}$ and $\mathbf{3 b}$ were prepared by the same general procedure used for $1{ }^{1}$

$\$$ The syntheses of $\mathrm{PhC}\left(=\mathrm{NCH}_{2} \mathrm{X}\right) \mathrm{Me}(\mathrm{X}=\mathrm{LG})$ were carried out analogously to the above imines, starting from a ketone and the appropriate amine. However, attempts to synthesize $\mathrm{H}_{2} \mathrm{NCH}_{2} \mathrm{X} \cdot \mathrm{HCl}(\mathrm{X}=\mathrm{Ms}$, Ts, oxazole) proved fruitless.

$\S \mathrm{PhCH}(\mathrm{Me}) \mathrm{N}=\mathrm{CHCCl}_{3}$ was prepared, rather than its isomer $\mathrm{PhC}$ $\left(=\mathrm{NCH}_{2} \mathrm{CCl}_{3}\right) \mathrm{Me}$, since its synthesis is easier and since it is known that under the conditions of Scheme $1, \mathrm{R}_{2} \mathrm{CHN}=\mathrm{CHCN}$ undergoes isomerization to yield $\mathrm{R}_{2} \mathrm{C}=\mathrm{NCH}_{2} \mathrm{CN}^{3}$ 


\section{Aziridines 4 and azirines 5}

Direct and indirect methods were used to probe the intermediacy of the three-membered heterocycles postulated for both pathways $a$ and $b$ in the mechanism of Scheme 3 . The following section describes how the search for evidence of the mechanism was approached through the study of these compounds. Indirect tests were carried out by investigating the reactivity of compounds $\mathbf{4}$ and $\mathbf{5}$ under the conditions of Scheme 1. Direct evidence of an intermediate was sought through NMR analysis of the reaction $\mathbf{1} \longrightarrow \mathbf{2}$

\section{Reaction of aziridines}

For the synthesis of an intermediate in the mechanism shown in Scheme 3, two general considerations led to the choice of 2-cyano-3-phenylaziridine $\mathbf{4 c}$ (Scheme 4), as a model com-

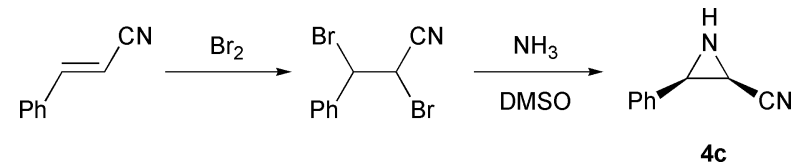

Scheme 4 Synthesis of 2-cyano-3-phenylaziridine $4 \mathbf{c}$.

pound: (i) as described above, the rearrangement $\mathbf{1} \longrightarrow \mathbf{2}$ occurs more readily on the benzaldehyde-derived imine $\mathrm{PhC}\left(=\mathrm{NCH}_{2}\right.$ $\mathrm{CN}) \mathrm{H}$ 1c with respect to ketone-derived imines; (ii) both reaction pathways ( $a$ and b) of compounds $\mathbf{1}$ in Scheme 3, require an aziridine as a common precursor, and $\mathbf{4 c}$ was one of the more readily accessible synthetically. ${ }^{9}$ Thus 2-cyano-3phenylaziridine was obtained in the cis configuration by a literature method, ${ }^{9}$ by reacting $\alpha, \beta$-dibromocinnamonitrile with dry ammonia. Once prepared, the aziridine $4 \mathbf{c}$ was made to react under the same conditions as for 1c. No reaction whatsoever occurred [eqn. (2)] and the reagent was recovered unchanged. This observation allowed us to rule out path $b$ of Scheme 3

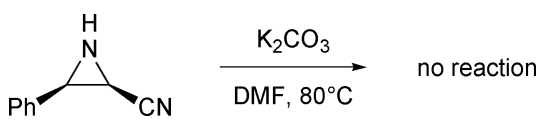

Path a of Scheme 3 implies the initial deprotonation of the reactant imine $\mathbf{1}$, followed by ring closure and $\mathrm{CN}^{-}$expulsion. The proposed ring closure is thermal, 4-electron, conrotatory, and allowed by the Woodward-Hoffmann rules. ${ }^{10}$ Scheme 5

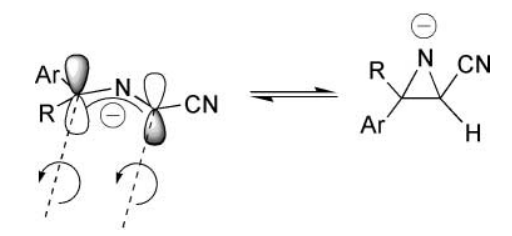

Scheme 5 Electrocyclic ring closure of $\mathbf{1}^{-}$

shows the allylic anion type HOMO of $\mathbf{1}^{-}$, which controls the course of the reaction, and its conrotatory closure to the intermediate cyclized anion. In this case, the subsequent step of cyanide elimination (path a of Scheme 3), to give the $2 \mathrm{H}$ azirine, must necessarily be favored over protonation at the nitrogen under the investigated conditions, to avoid the bottleneck posed by the aziridine of path $b$. The mechanistic analogy is again with the benzoin condensation, ${ }^{8}$ where the intermediate, with a negative charge on a heteroatom in the $\alpha$ position with respect to the $\mathrm{CN}$, prefers to eliminate cyanide, rather than to protonate at the oxygen (Fig. 1). To test this hypothesis the synthesis of an appropriate $2 \mathrm{H}$-azirine was undertaken.
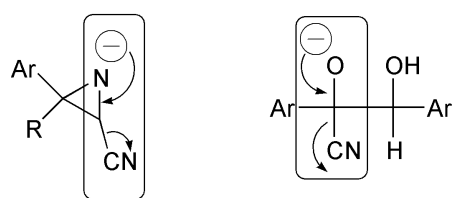

Fig. 1 Comparison between Scheme 4 and the benzoin condensation.

\section{Reaction of $2 \mathrm{H}$-azirine}

2,2-Diphenyl- $\mathrm{H}$-azirine $\mathbf{5 b}$ - the proposed intermediate for the rearrangement of $\mathrm{PhC}\left(=\mathrm{NCH}_{2} \mathrm{CN}\right) \mathrm{Ph} \mathbf{1 b}$ to diphenylacetonitrile $\mathbf{2 b}$-was synthesized, ${ }^{6,11}$ as shown in Scheme 6, by

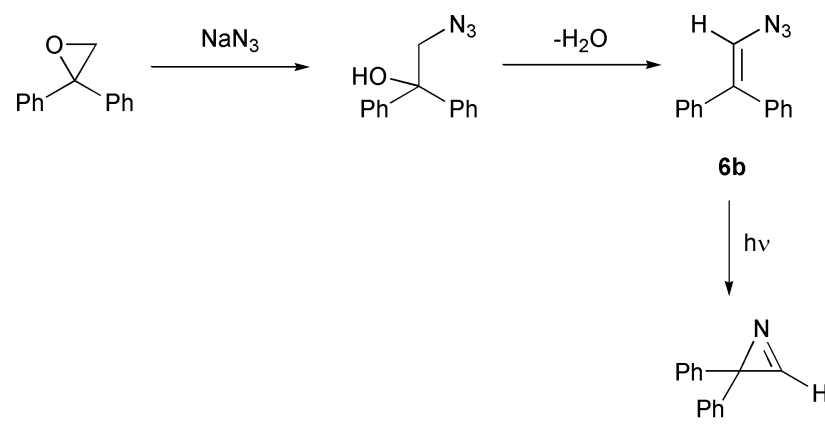

5b

Scheme 6 Synthesis of 2,2-diphenyl-2H-azirine $\mathbf{5 b}$.

irradiation of diphenylvinyl azide $\mathbf{6 b}$. Since $2 H$-azirines are quite air sensitive, once a $37 \%$ yield was reached, $\uparrow$ the solvent $\left(\mathrm{CDCl}_{3}\right)$ was immediately removed with a stream of nitrogen, and the mixture containing $\mathbf{5 b}$ was set to react at $150{ }^{\circ} \mathrm{C}$ with $\mathrm{K}_{2} \mathrm{CO}_{3}$ in DMF. Rewardingly, the reaction yielded predominantly diphenylacetonitrile $\mathbf{2 b}$ [85\%, eqn. (3)] along with $15 \%$ phenylindole, known to derive from the thermal treatment of 6b. ${ }^{6}$ This result supported the mechanism delineated in path a of Scheme 3 for the transformation $\mathbf{1} \longrightarrow \mathbf{2}$, although some doubt still persisted as to whether the vinyl azide $\mathbf{6 b}$, present in the reaction mixture, might itself have generated diphenylacetonitrile $\mathbf{2 b}$ under the same conditions. This hypothesis was ruled out by treating compound $6 \mathbf{b}$ at $150{ }^{\circ} \mathrm{C}$ with $\mathrm{K}_{2} \mathrm{CO}_{3}$ in DMF: benzophenone $(74 \%)$ and phenylindole $(23 \%)$ were the only products.

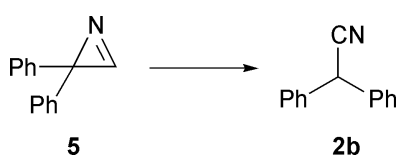

Having established that nitriles $\mathbf{2}$ can originate from azirines $\mathbf{5}$, direct evidence for the intermediacy of azirines $\mathbf{5}$ in the overall rearrangement of Scheme 1 was sought. This was done by ${ }^{1} \mathrm{H}$ NMR monitoring of the reaction of $N$-(diphenylmethylene)cyanomethylamine $\left[\mathrm{PhC}\left(=\mathrm{NCH}_{2} \mathrm{CN}\right) \mathrm{Ph}, \mathbf{1 b}\right]$ at $150{ }^{\circ} \mathrm{C}$, in DMF- $d_{7}$, and with $\mathrm{K}_{2} \mathrm{CO}_{3}$. The reaction proceeded as expected, with the disappearance of the $2 \mathrm{H}$ methylene singlet of $\mathbf{1 b}$ $(4.5 \mathrm{ppm})$ and the appearance of the $1 \mathrm{H}$ singlet of diphenylacetonitrile $\mathbf{2 b}(6.0 \mathrm{ppm})$. The signal at $10.7 \mathrm{ppm}$ - ascribable to the $2 \mathrm{H}$-azirine $\mathbf{5 b}$ - was detected, and remained at a constant intensity with respect to the starting material $\mathrm{PhC}\left(=\mathrm{NCH}_{2} \mathrm{CN}\right)$ $\mathrm{Ph}, \mathbf{1 b}$ until the reaction was over (Fig. 2).

From a mechanistic standpoint, the general scenario appeared clear: path a of Scheme 3, shown in Scheme 4, was

- Yield calculated by acquiring a ${ }^{1} \mathrm{H}$ NMR spectrum of the reaction mixture, and by integrating the peak of the proton in the 2-position of the $2 \mathrm{H}$-azirine $\mathbf{5 b}(10.2 \mathrm{ppm}),{ }^{13}$ relative to that of the vinyl proton of $\mathbf{6 b}$ $(6.7 \mathrm{ppm})$. This experiment also provided direct confirmation of the NMR resonance frequency of the azirine proton, which is reported in the literature, but with some ambiguity on the synthetic procedure. 


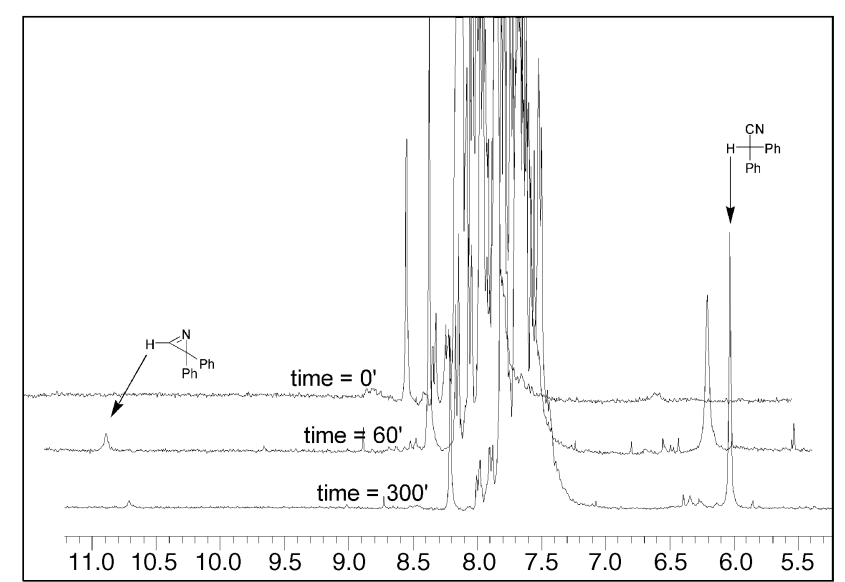

Fig. $2{ }^{1} \mathrm{H}$ NMR of reaction $\mathrm{PhC}\left(=\mathrm{NCH}_{2} \mathrm{CN}\right) \mathrm{Ph}, \mathbf{1 b} \longrightarrow \mathrm{Ph}_{2} \mathrm{CH}(\mathrm{CN})$ $\mathbf{2 b}$, collected at time intervals.

validated experimentally and offered a plausible pattern for the rearrangement $\mathbf{1} \rightarrow \mathbf{2}$. However, for a definitive explanation, one question remained to be answered. The intramolecular reaction shown in path a implied that the cyano group of the product nitrile 2 had to originate exclusively from the imine fragment $\left(=\mathrm{N}-\mathrm{CH}_{2}-\right)$ of the reactant. By contrast, as determined by the isotope labeling experiments carried out with $\mathrm{PhC}\left(=\mathrm{NCH}_{2}{ }^{13} \mathrm{CN}\right) \mathrm{Me}\left(1 \mathrm{a}^{*}\right),{ }^{4}$ a fraction $(32 \%)$ of the $\mathrm{CN}$ incorporated in the nitrile $2 \mathrm{a}$ resulted from the starting nitrile functionality of $1 a^{*}$ [eqn. (4)]. This isotope distribution (not explainable by path a, but partially accounted for by path $b$ ), was rationalized by means of a simple cross-over experiment.

$$
{ }_{1 \mathbf{a}^{*},{ }^{13} \mathrm{C}=99 \%} \stackrel{\mathrm{Ca}^{12} \mathrm{C} /{ }^{13} \mathrm{C}=68 / 32}{\longrightarrow{ }_{\mathrm{CH}_{3}} \mathrm{CN}}
$$

\section{Reaction of phenylacetonitrile $2 \mathrm{c}$ with ${ }^{13} \mathrm{CN}^{-}$}

A cross-over experiment had been previously reported by us, ${ }^{4}$ and it had shown that under the conditions of Scheme 1, the reaction of $1 \mathrm{a}$ in the presence ${ }^{13} \mathrm{C}$-labeled sodium cyanide, yielded product $\mathrm{PhCH}(\mathrm{Me}){ }^{13} \mathrm{CN} 2 \mathbf{a}^{*}$ with $15 \%{ }^{13} \mathrm{C}$ enrichment. Although this result did not exclude an intermolecular attack of ${ }^{13} \mathrm{CN}$ on the reagent, the existing evidence for the intramolecular character of the reaction $\mathbf{1} \longrightarrow \mathbf{2}$, strongly suggested that the isotope scrambling occurred on the product nitrile $\mathbf{2}$, after the imine had reacted. A more in-depth review of the literature, supported this hypothesis. ${ }^{12}$

When phenylacetonitrile $\mathbf{2 c}$ was allowed to react directly with ${ }^{13} \mathrm{C}$-labeled sodium cyanide under the conditions of Scheme 1, a significant isotopic enrichment $(25 \%)$ of the product nitrile $2 \mathrm{c}$ was observed. Therefore, since the $\mathrm{CN}$ scrambling was the final, independent step, from the preceding ones involving imines $\mathbf{1}$, the intramolecular mechanism of Scheme 4 appeared compatible with the results also obtained for the ${ }^{13} \mathrm{C}$-labeled imine $\left[\mathbf{1} \mathbf{a}^{*}\right.$, eqn. (4)]. The $\mathrm{CN}^{-}$released from the reaction of imines 1 accounted for the observed scrambling. ${ }^{4}$

\section{Conclusions}

The results presented allow an overall mechanism for the transformation $\mathbf{1} \longrightarrow \mathbf{2}$, under the conditions of Scheme 1 , to be proposed, such as the one shown in path a of Scheme 3. It involves a thermal electrocyclic 4-electron reaction followed by a $\mathrm{CN}$ elimination step. While it is observed that the aziridine 3 does not react at all, and therefore cannot be an intermediate, direct and indirect evidence supports the intermediacy of a $2 \mathrm{H}$-azirine, which does give the expected nitrile under the conditions investigated.
The reaction is very sensitive to the nature of the reacting imines. Imines derived from aldehydes react much faster than those prepared from ketones, indicating that the proposed intramolecular ring closure is influenced by steric factors. However, even the sterically undemanding methyl group in the $\alpha$ position of imine 1 disfavors the intramolecular ring closure to give the $2 \mathrm{H}$-azirine ring, presumably by electron donating effects.

The data available to date seem to indicate that leaving groups other than $\mathrm{CN}^{-}$inhibit the reaction. Current efforts are aimed at extending its scope to other substrates, and some preliminary data indicate that compounds such as $\mathrm{PhC}=$ $\left.\mathrm{NCH}_{2} \mathrm{CO}_{2} \mathrm{CH}_{3}\right) \mathrm{H}$, derived from aldehydes, do in fact undergo the same rearrangement to yield phenylacetonitrile. This observation may open the way to a more general application of the reaction, and to its use with reagents possessing poorer leaving groups. To this end, there are significant challenges in the syntheses of imines 1 with such characteristics, which may follow the same rearrangement mechanism, thereby paving the way to new synthetic applications.

\section{Experimental}

Imine $\mathrm{PhC}\left(=\mathrm{NCH}_{2} \mathrm{CF}_{3}\right) \mathrm{Me}$ (3b) was obtained through the condensation of acetophenone ( $2 \mathrm{~g}, 16.7 \mathrm{mmol})$ with 2,2,2trifluoroethylamine hydrochloride salt $\left(\mathrm{CF}_{3} \mathrm{CH}_{2} \mathrm{NH}_{2} \cdot \mathrm{HCl}\right){ }^{1,10}$ Yield of distilled product $\left(\mathrm{bp}=65^{\circ} \mathrm{C} / 0.8 \mathrm{mmHg}\right): 1.8 \mathrm{~g}(54 \%)$. ${ }^{1} \mathrm{H}$ NMR $\left(\mathrm{CDCl}_{3}\right) \delta 7.87-7.83$ and 7.45-7.35 (m, $\left.4 \mathrm{H}, \mathrm{Ph}\right), 4.00$ (qq, $\left.2 \mathrm{H}, J=9.6 \mathrm{~Hz}, J^{\prime}=0.98 \mathrm{~Hz}\right), 2.28\left(\mathrm{t}, 3 \mathrm{H}, \mathrm{CH}_{3}, J^{\prime}=0.98\right.$ $\mathrm{Hz})$. Mass spectrum $(70 \mathrm{eV}) \mathrm{m} / \mathrm{z}$ (relative intensity): $201\left(\mathrm{M}^{+}\right.$, 30\%), 200 (32), 187 (10), $186\left(\mathrm{M}^{+}-\mathrm{CH}_{3}, 100\right), 132\left(\mathrm{M}^{+}-\mathrm{CF}_{3}\right.$, 5), 124 (18), 104 (24), 103 [PhC(Me)= $\left.\mathrm{N}^{+}, 10\right], 91$ (26), 83 (10), 77 (18), 51 (10).

Compound 3b $(0.2 \mathrm{~g}, 0.99 \mathrm{mmol})$ was made to react under the conditions of Scheme 1, during which elimination of $\mathrm{HF}$ took place. After $310 \mathrm{~min}$ in refluxing $\mathrm{DMF}$, the conversion was $54 \%$ (by GC) and a mixture of $E / Z$ isomers $[\mathrm{PhC}(=\mathrm{NCH}=$ $\left.\mathrm{CF}_{2}\right) \mathrm{Me}: \mathbf{3 e}(45 \%)$ and $\left.\mathbf{3} \mathbf{e}^{\prime}(3 \%)\right]$ was obtained. Structures were assigned by GC-MS. Mass spectrum $(70 \mathrm{eV}) \mathrm{m} / \mathrm{z}$ (relative intensity): 3e, $181\left(\mathrm{M}^{+}, 47 \%\right), 166\left(\mathrm{M}^{+}-\mathrm{Me}, 100\right), 154$ (15), 104 (25), 103 (12), 77 (38), 51 (13); 3e' $181\left(\mathbf{M}^{+}, 37 \%\right), 104$ $\left(\mathrm{M}^{+}-\mathrm{NCH}=\mathrm{CF}_{2}, 10\right), 103(100), 77$ (25), 51 (11).

Imine $\mathrm{PhCH}(\mathrm{Me}) \mathrm{N}=\mathrm{CHCCl}_{3}$ (3f) was obtained through the condensation of $\alpha$-methylbenzylamine $(0.5 \mathrm{~g}, 4.1 \mathrm{mmol})$ with 2,2,2-trichloroacetaldehyde. ${ }^{12}$ Yield of distilled product ( $\mathrm{bp}=$ 62-65 $\left.{ }^{\circ} \mathrm{C} / 0.4 \mathrm{mmHg}\right): 0.73 \mathrm{~g}(70 \%) .{ }^{1} \mathrm{H}$ NMR $\left(\mathrm{CDCl}_{3}\right) \delta 7.77(\mathrm{~s}$, $1 \mathrm{H}, \mathrm{CH}=), 7.37-7.32(\mathrm{~m}, 4 \mathrm{H}, \mathrm{Ph}), 4.68(\mathrm{q}, 1 \mathrm{H}, J=6.7 \mathrm{~Hz}), 1.59$ (d, $3 \mathrm{H}, \mathrm{CH}_{3}, J=6.7 \mathrm{~Hz}$ ). Mass spectrum $(70 \mathrm{eV}) \mathrm{m} / \mathrm{z}$ (relative intensity): $249\left(\mathrm{M}^{+},<1 \%\right), 132\left(\mathrm{M}^{+}-\mathrm{CCl}_{3}, 7\right), 106(11), 105$ (100), 77 (14), 51 (10).

Compound $3 f(0.2 \mathrm{~g}, 0.80 \mathrm{mmol})$ was made to react under the conditions of Scheme 1. As already reported for similar conditions, ${ }^{12}$ elimination of $\mathrm{HCl}$ took place. After $90 \mathrm{~min}$ in refluxing DMF, the conversion was $64 \%$ (by GC) and a mixture of $E / Z$ isomers $\left[\mathrm{PhC}\left(=\mathrm{NCH}=\mathrm{CCl}_{2}\right) \mathrm{Me} \mathrm{3g}(41 \%)\right.$ and $\left.\mathbf{3 g ^ { \prime }}(20 \%)\right]$ was obtained. Structures were assigned by GC-MS. Mass spectrum $(70 \mathrm{eV}) \mathrm{m} / \mathrm{z}$ (relative intensity): 3g, $215\left(\mathrm{M}^{+}+2,33\right), 213\left(\mathrm{M}^{+}\right.$, 50\%), 202 (11), 200 (66), 199 (11), $198\left(\mathrm{M}^{+}-\mathrm{CH}_{3}, 100\right), 180$ (11), 178 (33), 138 (11), 136 (17), 104 (63), 103 (22), 102 (16), 77

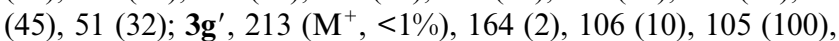
$103(10), 77(15)$

Imine $\mathrm{PhC}\left(=\mathrm{NCH}_{2} \mathrm{CN}\right) \mathrm{H}$ 1c was obtained through the condensation of benzaldehyde $(1.0 \mathrm{~g}, 9.4 \mathrm{mmol})$ with aminoacetonitrile hydrochloride. ${ }^{1}$ Yield of distilled product $(\mathrm{bp}=$ $110{ }^{\circ} \mathrm{C} / 0.7 \mathrm{mmHg}$, lit., $\left.{ }^{13} 92-93{ }^{\circ} \mathrm{C} / 0.1 \mathrm{mmHg}\right): 0.60 \mathrm{~g}(44 \%)$. Characterization data of $\mathbf{1 c}$ are in ref. 14 .

\section{cis-2-Cyano-3-phenylaziridine (4c) ${ }^{9}$}

$4 \mathbf{c}$ was obtained by saturating a solution of $\alpha, \beta$-dibromocinnamonitrile $(650 \mathrm{mg}, 2.14 \mathrm{mmol})$ solution of $\alpha, \beta$-dibromocin- 
namonitrile in DMSO $(20 \mathrm{ml})$ with dry ammonia gas for one hour. The mixture was stirred overnight at room temperature, poured into brine, and extracted with dichloromethane. The organic layer was washed twice with $50 \mathrm{ml}$ of water, dried over sodium sulfate and evaporated to dryness. The product solidified $(55 \%$ yield $)$ upon standing. ${ }^{1} \mathrm{H}$ NMR $\left(\mathrm{CDCl}_{3}\right) \delta 7.5-7.3$ $(\mathrm{m}, 5 \mathrm{H}), 3.56$ and $3.02\left(\mathrm{AB}\right.$ systems, $J_{1}=5.9 \mathrm{~Hz}, J_{2}=9.7 \mathrm{~Hz}$, cis-aziridine ring protons $\|), 1.72(\mathrm{t}, 1 \mathrm{H}, J=9.7 \mathrm{~Hz})$.

\section{2-Azido-1,1-diphenylethylene (6b)}

Compound $\mathbf{6 b}$ was prepared following known methods starting from diphenylethylene oxide, via 1,1-diphenyl-2-azidoethanol. Dehydration of the latter was conducted by the following procedure, adapted from the literature: ${ }^{15}$ 1,1-diphenyl-2-azidoethanol ( $1 \mathrm{~g}, 4.2 \mathrm{mmol})$ was dissolved in $7 \mathrm{ml}$ of dry DMF, 3.0 $\mathrm{ml}$ of pyridine were added, and the mixture was cooled to $15^{\circ} \mathrm{C}$ in an ice bath. In a separate flask, $\mathrm{SO}_{2}$, obtained by the dropwise addition of sulfuric acid to $\mathrm{Na}_{2} \mathrm{SO}_{3}$, was bubbled through $10 \mathrm{ml}$ of methanesulfonyl chloride ( $\mathrm{MsCl}$, Aldrich reagent), until a $5 \%$ wt solution of $\mathrm{SO}_{2}$ in $\mathrm{MsCl}$ was obtained. An aliquot ( $2 \mathrm{ml}$, corresponding to $26 \mathrm{mmol}$ of $\mathrm{MsCl}$ ) of $\mathrm{MsCl}-\mathrm{SO}_{2}$ was added to the 2-azido-1,1-diphenylethylene solution over $15 \mathrm{~min}$, maintaining the temperature of the mixture below $15^{\circ} \mathrm{C}$, during which the solution turned deep red. It was allowed to stir overnight at room temperature. Work-up consisted of the dropwise addition of $3 \mathrm{ml}$ water, followed by a large excess $(15 \mathrm{ml})$, and extraction of the mixture with methylene chloride $(15 \mathrm{ml})$. The organic phase was washed successively with saturated brine, half saturated brine, and water, and dried over $\mathrm{Na}_{2} \mathrm{SO}_{4}$. It was then filtered, and evaporated to dryness at reduced pressure Purification was carried out by flash chromatography eluting with a $1: 1$ mixture of toluene and petroleum ether $\left(R_{\mathrm{f}}=0.55\right)$. Yield $300 \mathrm{mg}(35 \%)$. ${ }^{1} \mathrm{H}$ NMR $\left(\mathrm{CDCl}_{3}\right) \delta 7.4-7.2(\mathrm{~m}, 10 \mathrm{H})$, $6.7(\mathrm{~s}, 1 \mathrm{H})$. IR $v_{\max }($ neat $) / \mathrm{cm}^{-1} 2102\left(\mathrm{~N}_{3}\right), 1612(\mathrm{C}=\mathrm{C})$. Mass spectrum $(70 \mathrm{eV}) \mathrm{m} / \mathrm{z}$ (relative intensity): $193\left(\mathrm{M}^{+}-\mathrm{N}_{2}, 100\right)$, 165 (42), 139 (7).

\section{2,2-Diphenyl-2H-azirine (5b) and its reaction under the conditions of Scheme 1}

2-Azido-1,1-diphenylethylene (200 mg, $0.9 \mathrm{mmol}$ ) was dissolved in $10 \mathrm{ml} \mathrm{CDCl}_{3}$ in a nitrogen atmosphere in a Pyrex jacketed reactor maintained at $-20{ }^{\circ} \mathrm{C}$ by circulating ethanol. The solution was irradiated with a medium pressure $\mathrm{Hg}$ lamp (filter cut-off $\lambda<350 \mathrm{~nm}$ ). The tendency of atmospheric humidity to condense on the reactor was controlled by means of a nitrogen flow over the part exposed to the lamp. After $90 \mathrm{~min}-$ utes, a portion of the solution was analyzed by ${ }^{1} \mathrm{H}$ NMR which showed the presence of $37 \%$ of the desired $2 \mathrm{H}$-azirine $\mathbf{5 b}$, the remaining being substrate $\mathbf{6 b}$, indicating that the reaction had proceeded cleanly. 5b: ${ }^{1} \mathrm{H}$ NMR $\left(\mathrm{CDCl}_{3}\right) \delta 10.2(\mathrm{~s}, 1 \mathrm{H}), 7.4-7.2$ $(\mathrm{m}, 10 \mathrm{H})$.

|| Aziridine cis-protons are known to have larger coupling constants and larger chemical shifts with respect to protons in the transconfiguration; in the latter case the signals of the protons should therefore be broad, while in the former two AB systems would be expected. The observed AB systems $\left(J_{1}=5.9 \mathrm{~Hz}, J_{2}=9.7 \mathrm{~Hz}\right)$ are therefore consistent with an aziridine in the cis-configuration. ${ }^{9}$
After removal of the $\mathrm{CDCl}_{3}$ with a stream of nitrogen (at $0{ }^{\circ} \mathrm{C}$ ), the residue containing 2,2-diphenyl- $2 \mathrm{H}$-azirine $\mathbf{5 b}$ was transferred to a $10 \mathrm{ml}$ flask containing $150 \mathrm{mg}(1.1 \mathrm{mmol})$ of $\mathrm{K}_{2} \mathrm{CO}_{3}$, using $5 \mathrm{ml}$ of dry DMF. The mixture was heated under nitrogen at $120{ }^{\circ} \mathrm{C}$ for 2 hours, and then analyzed by GC-MS. Along with $\mathbf{6 b}$, the mixture showed the presence of diphenylacetonitrile $\mathbf{2 b}(85 \%)$ and a small amount of phenylindole $(15 \%)$, all recognized by comparison with authentic samples. Diphenylvinyl azide $\mathbf{6 b}$ was made to react under the same conditions as $\mathbf{5 b}$. After 2 hours at $150{ }^{\circ} \mathrm{C}$, at complete conversion, $74 \%$ of benzophenone, $23 \%$ of phenylindole and $<3 \%$ of $\mathbf{2 b}$ were observed.

\section{Reaction of phenylacetonitrile $2 \mathrm{c}$ with ${ }^{13} \mathrm{CN}^{-}$}

Phenylacetonitrile $\left(50 \mathrm{mg}, 0.43 \mathrm{mmol}\right.$ ) was set to react at $120^{\circ} \mathrm{C}$ in a nitrogen atmosphere, with an equimolar amount of $\mathrm{Na}^{13} \mathrm{CN}$ in the presence of $\mathrm{K}_{2} \mathrm{CO}_{3}(90 \mathrm{mg}, 0.65 \mathrm{mmol})$ in $5 \mathrm{ml}$ of dry DMF. After 1 hour the mixture was analyzed by GC-MS, and the phenylacetonitrile showed a $25 \%$ isotope enrichment of ${ }^{13} \mathrm{C}$.

\section{Acknowledgements}

We wish to thank Professor Andrea Maldotti for assistance in the photochemical synthesis, and Dr Alfonso Zambon for helping with the calculations of the molecular orbital energies. The Consorzio Interuniversitario "la Chimica per l'Ambiente" (INCA) is also gratefully acknowledged for funding.

\section{References}

1 M. Selva, C. A. Marques and P. Tundo, Synth. Commun., 1995, 25, 369.

2 M. Selva, A. Bomben and P. Tundo, Synth. Commun., 1999, 29, 1561.

3 A. Perosa, M. Selva and P. Tundo, Tetrahedron Lett., 1999, 40, 7573.

4 A. Perosa, M. Selva and P. Tundo, J. Chem. Soc., Perkin Trans. 2, 1999,2485

5 R. G. Pearson, H. Sobel and J. Songstad, J. Am. Chem. Soc., 1968, 90, 319 .

6 W. Tumas, R. F. Foster and J. Brauman, J. Am. Chem. Soc., 1988, 110, 2714.

7 T. Aoki, N. Haga, Y. Sendo, T. Konoike, M. Yoshioka and W. Nagata, Tetrahedron Lett., 1985, 26, 339.

8 M. B. Smith and J. March, in March's Advanced Organic Chemistry, 5th edn., J. Wiley \& Sons, New York, 2001, p. 1243.

9 A. I. Ayi and R. Guedj, J. Chem. Soc., Perkin Trans. 1, 1983, 2045.

10 R. B. Woodward and R. Hoffmann, J. Am. Chem. Soc., 1965, 87, 395; H. C. Longuet-Higgins and E. W. Abrahamson, J. Am. Chem. Soc., 1965, 87, 2045; R. B. Woodward and R. Hoffmann, J. Am. Chem. Soc., 1965, 87, 2046.

11 K. Isomura, M. Okada and H. Taniguchi, Tetrahedron Lett., 1969, 46, 4073; K. Isomura, H. Taniguchi, M. Mishima, M. Fujio and Y. Tsuno, Org. Magn. Reson., 1977, 9, 559.

12 M. Jay, W. J. Layton and G. A. Digenis, Tetrahedron Lett., 1980, 21, 2621.

13 A. C. Davis and A. L. Levy, J. Chem. Soc., 1951, 3479.

14 O. Tsuge, K. Ueno, S. Kanemasa and K. Yorozu, Bull. Chem. Soc. Jpn., 1986, 59, 1809.

15 G. G. Hazen and D. W. Rosenburg, J. Org. Chem., 1964, 29, 1931. 